\title{
CONGENITAL SENSORY NEUROPATHY (HSAN II)
}

\author{
K. Venkata Chalam¹, B. S. Chakravarthy², P. Anila Sunandini ${ }^{3}$, K. S. Divya ${ }^{4}$, Y. Padmasri ${ }^{5}$
}

\section{HOW TO CITE THIS ARTICLE:}

K. Venkata Chalam, B. S. Chakravarthy, P. Anila Sunandini, K. S. Divya, Y. Padmasri. "Congenital Sensory Neuropathy (HSAN II)". Journal of Evolution of Medical and Dental Sciences 2015; Vol. 4, Issue 66, August 17; Page: 11551-11554, DOI: $10.14260 /$ jemds/2015/1665

ABSTRACT: A 5 year old girl having hereditary sensory neuropathy, type II manifesting as congenital absence of pain sensation and trophic changes in the skin is reported. This child presented with presented with multiple ulcers over hands and feet since 2 years of age. The ulcers were non-healing type with serosanguineous discharge. There is abnormal gait and weakness in upper and lower limbs. On examination there are deep ulcers measuring $5 \times 7 \times 2 \mathrm{cms}$ over left feet. Fingers of both hands and feet were mutilated with loss of phalanges, sensations to fine touch, pain and temperature are decreased bilaterally below the mid arm and feet, vibration sensations were normal, proprioception could not be tested due to deformities. Sensory and motor nerve conduction studies showed evidence of sensorimotor axonal neuropathy.

INTRODUCTION: The hereditary sensory and autonomic neuropathies (HSAN) includes a number of inherited disorders that are associated with sensory dysfunction (Altered pain and temperature, depressed reflexes) and differing degrees of autonomic dysfunction (Gastroesophageal reflux, Postural hypotention, Excessive sweating). Dyck and Ohta proposed the numerical classification of four distinct forms of HSAN. ${ }^{1}$

Clinical features, the degree of both sensory and autonomic dysfunction, helps in Diagnosis of these disorders. Biochemical evaluations, with pathologic examinations serving to further confirm differences. Treatments for all these disorders are supportive.

Congenital sensory neuropathy (HSAN II)

HSAN type II is very low. In prevalence worldwide.

CLINICAL PRESENTATION: HSAN II is non-progressive and presents in infancy or early childhood. It is characterized by profound sensory loss and pronounced hypotonia. HSAN II occurs sporadically or with autosomal recessive inheritance. There is no particular ethnic preponderance, or sex preference.

Till to date there is no increased incidence of consanguinity.

All peripheral sensations are affected but distribution of somatic involvement may alter. Pain, temperature, and position senses are involved. Trophic changes are present, especially in upper and lower extremities, as in our case.

Morvan is the physician who first described this disease and hence HSAN II been termed as "Morvan's" disease. The occurrence of 'painless whitlows' or acrodystrophic neuropathy).2,3

HSAN II is associated with repeated occurrence of unrecognized injuries and fractures of hands, feet, and limbs, as well as Charcot joints. ${ }^{4,5}$

Deep tendon reflexes are decreased and hypotonia is common. Hypotonia delays attainment of developmental milestones. Inspite of marked sensory abnormalities, other aspects of the neurological examination may be normal including mental function, cranial nerves, cerebellar and 


\section{CASE REPORT}

motor functions. There is no muscle atrophy or muscle weakness even though the tendon reflexes are decreased or absent.

PATHOLOGY: Sural nerve biopsy shows a marked reduction in nerve size and depletion of large and small myelinated fibers but only a slightly decreased number of unmyelinated fibers as in our case.

There are no cutaneous sensory receptors or nerve fibers are seen but catecholaminergic sympathetic fibers can be demonstrated by aldehyde induced fluorescence.

DIAGNOSIS: The diagnosis is based on documenting profound peripheral sensory involvement of both peripheral and cranial nerves, (This can be demonstrated by an absent axon flare after intradermal histamine). Clinical identification is done by the finding of a mutilating acropathy with a severe, distally pronounced impairment of all sensory qualities (Light touch sensation, position sense and vibratory perception, as well as pain and temperature perception). Supportive evidence consists of sel mutilation, hypotonia and delayed milestones, and normal somatic growth.

Abnormal vibratory thresholds, and quantitative sensory testing are shown with the neurophysiological evaluation. It may also reveal elevated thermal thresholds at the hands and feet 6 . Typically, nerve conduction studies confirm marked impairment of sensory nerve conduction velocities and absent sensory nerve action potentials, but motor nerve conduction velocities are at or slightly below the normal limit.

MANAGEMENT: Management is essentially symptomatic and preventative. If feeding problems compromise nutrition and if gastroesophageal reflux is also present, surgical options like fundoplication with gastrostomy is recommended. Sleep pneumograms are helpful if there is central apnea and if respiratory support is needed. Parents and patients education is very much required to learn how to avoid injury and how to be alert for signs of unrecognized trauma.

Early diagnosis is crucial for prevention of injury, self-mutilation and growth retardation. This case Report highlights the importance of assessment of pain sensation be a part of routine examination of newborn.

CASE REPORT: A 5 year old female child born of non-consanguineous marriage presented with multiple ulcers over hands and feet since 2 years of age. There was history of loss of pain and temperature sensations over hands and feet, followed by gradual ulceration and loss of fingers. The ulcers were non-healing type with serosanguineous discharge. There is abnormal gait and weakness in upper and lower limbs.

There is no history of fever and recurrent respiratory or gastrointestinal infections. There were no similar complaints in family. On examination there are deep ulcers measuring $5 \times 7 \times 2 \mathrm{cms}$ over left feet, base is fixed to underlying muscle, floor is covered with pale granulation tissue, edges were slopy, discharge from the ulcer is serosanguinous. Surrounding skin of feet is oedematous and hyperpigmented.

There is fanning of toes. Fingers of both hands and feet were mutilated with loss of phalanges, sensations to fine touch, pain and temperature are decreased bilaterally below the mid arm and feet, vibration sensations were normal, proprioception could not be tested due to deformities.

Peripheral nerves are not thickened. Sympathetic skin response is absent bilaterally below mid fore arm and feet. Motor examination power is normal. Deep tendon reflexes are absent in upper 


\section{CASE REPORT}

and lower limbs. Other system examination is normal. There was no other abnormality detected in intelligence, cranial nerve examination is normal. Routine blood investigations are normal.

Sensory and motor nerve conduction studies showed evidence of sensorimotor axonal neuropathy. Slit skin smear from patient is normal.

The case is diagnosed as hereditary sensory axonal neuropathy-type 2, managed conservatively with regular dressings, avoidance of physical trauma, hand and foot care.

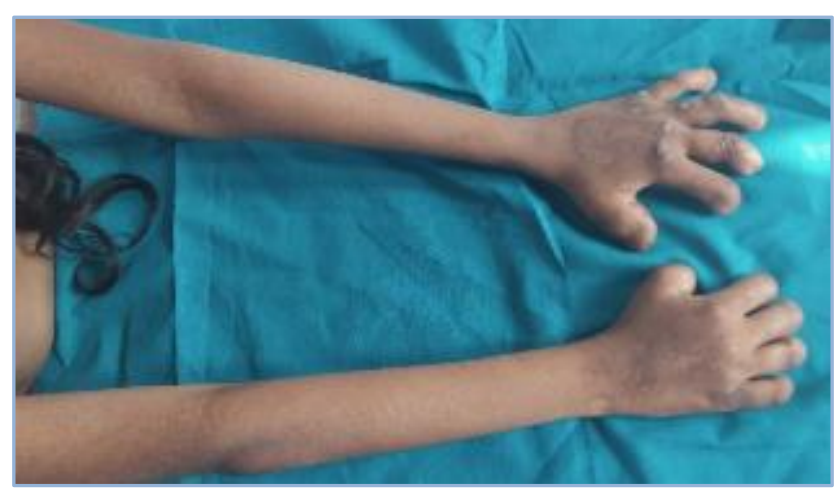

Fig. 1: Mutilated fingers with loss of phalanges

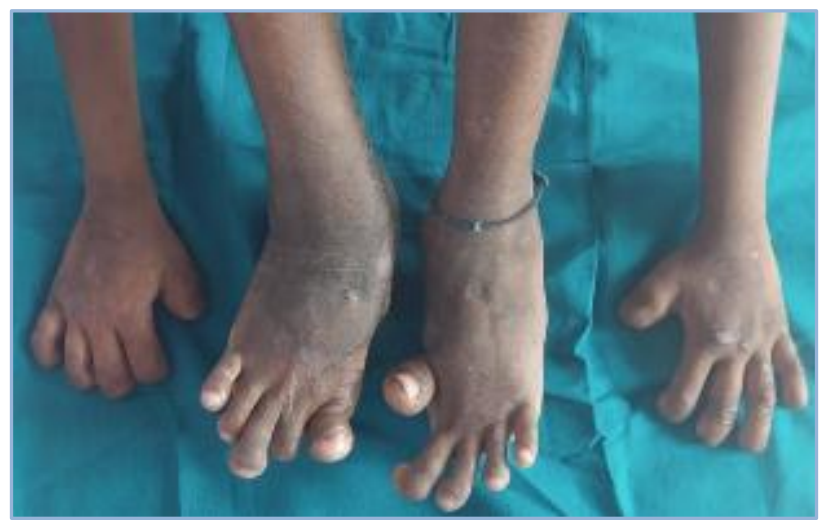

Fig. 2: Fanning of toes

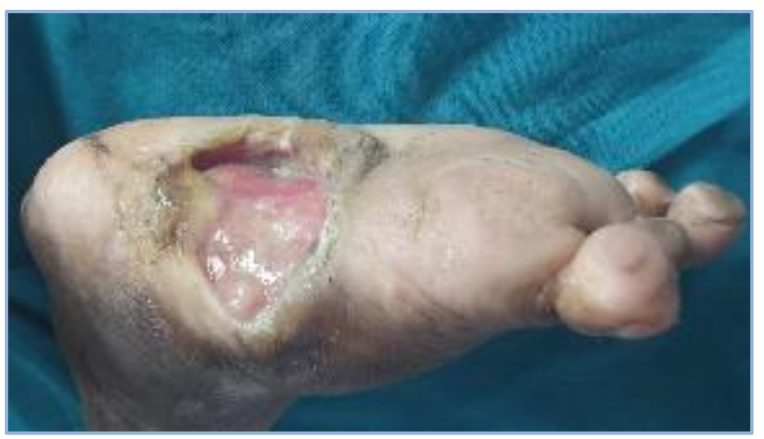

Fig. 3: Deep ulcer over left foot 


\section{REFERENCES:}

1. Dyck P, Ohta M: Neuronal atrophy and degeneration predominantly affecting peripheral sensory neurons. In Peripheral Neuropathy. Volume 2. Edited by Dyck PJ, Thomas PK, Lambert EH. Philadelphia: WB Saunders; 1975: 791.

2. Barry JE, Hopkins IJ, Neal BW: Congenital sensory neuropathy. Arch Dis Child 1974, 49:128132. PubMed Abstract.

3. Hilz MJ: Assessment and evaluation of hereditary sensory and autonomic neuropathies with autonomic and neurophysiological examinations. Clin Auton Res 2002, 12(Suppl 1): I33-I43. PubMed Abstract | Publisher Full Text.

4. Axelrod FB: Hereditary sensory and autonomic neuropathies. Familial dysautonomia and other HSANs. Clin Auton Res 2002, 12(Suppl 1):I2-I14. PubMed Abstract | Publisher Full Text.

5. Axelrod FB: Autonomic and Sensory Disorders. In Principles and Practice of Medical Genetics. Volume 3. 5th edition. Edited by Rimoin DL, Connor JM, Pyeritz RE, Korf BR. Edinburgh: Churchill Livingstone; 2007: 2802-2816.

6. Dyck PJ: Neuronal atrophy and degeneration predominantly affecting peripheral sensory and autonomic neurons. In Peripheral Neuropathy. Volume 2. Edited by Dyck PJ, Thomas PK, Griffin JW, Low PA, Podulso JF. Philadelphia: W.B. Saunders; 1993:1065-1093.

\section{AUTHORS:}

1. K. Venkata Chalam

2. B. S. Chakravarthy

3. P. Anila Sunandin

4. K. S. Divya

5. Y. Padmasri

\section{PARTICULARS OF CONTRIBUTORS:}

1. Assistant Professor, Department of DVL, Andhra Medical College.

2. Assistant Professor, Department of Paediatrics, Rangaraya Medical College.

3. HOD, Department of DVL, Andhra Medical College.

4. Senior Resident, Department of DVL, Andhra Medical College.

FINANCIAL OR OTHER COMPETING INTERESTS: None
5. Post Graduate Student, Department of DVL, Andhra Medical College.

\section{NAME ADDRESS EMAIL ID OF THE CORRESPONDING AUTHOR:}

Dr. K. Venkata Chalam, Department of Dermatology, GHT Clinic, Dwarakanagar, $3^{\text {rd }}$ lane, Opposite Anupama Nursing Home, Vishakapatnam-530016.

E-mail: bhimisetti@gmail.com

Date of Submission: 10/08/2015. Date of Peer Review: 11/08/2015. Date of Acceptance: 14/08/2015. Date of Publishing: 17/08/2015. 